\title{
Letters
}

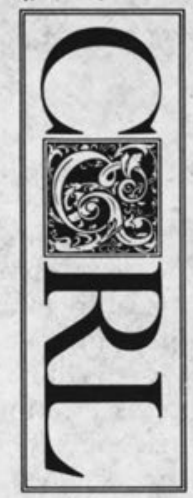

\section{CREATIVE RESEARCH}

To the Editor:

While Amusi Odi ${ }^{1}$ has clearly rendered a service to library and information science by calling attention to a methodological defect that he has recognized in our research, it might have been a greater service had he desisted from frightening us to death in introducing the problem. For a profession already aquiver with self-doubt, his apparent sweeping putdown of our collective research could be traumatic: "A disturbing trend pervades library and information science and, in fact, most studies in the social sciences today. This trend is quantification of human behavior." This is followed by an examination of scientific method and discussion of the futility of research studies that hinge on quantitative description and analysis of human behavior in units or categories that are inherently vague.

No doubt the disease he discusses exists in library and information science. But is it indeed serious? I have made a small, quick survey to try to answer this question. The results (preliminary, of course) are reassuring. The mis-quantification of behavior in library and information science research amounts to neither a terminal brain tumor nor a raging epidemic. It is more like a patch of poison ivy on the posterior part. The analysis that led to this conclusion involved considerable subjective judgment; other readers may wish to check for themselves.

It was not possible to determine from the paper exactly what research material Odi had reviewed and in what way. The paper gives no numbers to quantify the "disturbing trend, " nor any specific instances of bad research as illustrations. It turns almost at once to the restricted area of research on library administration and to general categories of treatment of behavior in that area. While, again, no numbers or citations are given, the types of weak methodology discussed are said to come from a careful look at Dissertation Abstracts International (DAI) for the last ten years. Therefore, my survey was an examination of virtually the same dissertation literature, looking for evidence of research studies involving the quantification of behavior.

To save on the time and energy that would be involved in coping with the many heavy volumes of DAI, I used instead Charles H. Davis's compact bibliography and index of library science dissertations; ${ }^{2}$ it covers 915 dissertations from 1930 to 1980 , but omits abstracts in the listing. Pertinent headings in the subject index generated a group of 66 dissertations addressed to library administration (18 from the 1935-1971 period, 42 from the 1972-1980 period). Using personal judgment in interpreting the titles, these 66 dissertations were divided into three subgroups: those that probably did employ quantification of behavior, those that probably did not employ it, and those that could not be judged from the abridged information available. The respective counts were 24,30 , and 12 . This means that the behavior quantification approach was used in somewhere between 36 and 54 percent of the full group. The suspect approach appeared first in 1961. It has been used in one or more dissertations each year since 1972 . 
While the figures just presented may seem to some to support the notion of a disturbing trend, it should be noted that the sampled research area, research on library administration, appears to be the only one in our field that makes significant use of the suspect approach. Library administration research accounts for barely 7 percent of the dissertation literature of the field. Dissertations, in turn, are only a small percentage of the total research literature. My firm impression from quite a few years of editing one of our secondary services $^{3}$ is that the behavioral approach is far rarer in the journal and report literature than it is in dissertations. This leaves us, it seems, with a "disturbing trend" in only the small area of research on library administration and possibly some other even smaller areas. Even there, things may not be too bad. From the counts in my survey there is some suggestion that use of the behavioral approach has been declining slowly after peaking in the mid-1970s; at any rate, it has not been growing. So it appears that we need not be too worried or ashamed about the general quality of research in the field-that is, not on account of the behavioral quantification problem. This is not the place to bring up other problems with our research.

There is a final comment to be made regarding Odi's exposition of scientific method. While it was effective in clarifying the problem of behavioral quantification, it rests on an excessively narrow premise that would cause trouble in other contexts. Odi starts his methodological analysis with: "What is the purpose of research? It seems to me that, briefly stated, the whole purpose of research is the development of theory." The discourse that follows reflects and repeats this view. However, not everyone shares the view that development of theory is the sole purpose of research (certainly not most librarians and information professionals). Many respected authorities on science have stated other purposes or products of research that can be validly pursued instead of or in addition to theory development or each other. In a book that has been around for seventeen years, ${ }^{4}$ I compiled and discussed the several types of research objectives or products. Six categories were found to be operationally useful: description, definition, theory, explanation of observed phenomena, prediction of future phenomena, and manipulative prescription to expand human capability or control. Odi's discussion does, in fact, touch on all but the last of these, but not in the sense of possible major objectives. Most librarians, I would guess, are far more interested in improving their capabilities to serve clients and sponsors than in perfecting theory; I would hope that they recognize too that improvement in theory can be helpful in establishing improved services although it is not the only means to that end.

BEN-AMI LIPETZ

School of Library and Information Science

State University of New York at Albany

\section{REFERENCES}

1. Amusi Odi, "Creative Research and Theory Building in Library and Information Sciences," College \& Research Libraries 43:312-19 (July 1982).

2. Charles H. Davis, comp., Library Science: A Dissertation Bibliography (Ann Arbor: University Microfilms International, 1980$), 30 \mathrm{p}$.

3. Information Science Abstracts 1 (1966) to 15 (1980).

4. Ben-Ami Lipetz, The Measurement of Efficiency of Scientific Research (Nassau, N.Y.: Intermedia, Inc., 1965), p.71-124.

\section{To the Editor:}

Mr. Lipetz's concerns about my paper may be succinctly summarized thus:

In the first place, while admitting that misapplication of quantification exists in the library and information sciences, he contends that the problem is not a serious one. It is, in his own words, "neither a terminal brain tumor nor a raging epidemic."

Second, Mr. Lipetz takes issue with my assertion that the purpose of scientific research is the development of theory. The rest of his letter to the editor is an attempt to provide supportive evidence to his concerns. Let me first respond to his contentions and then put the perspectives of my paper in relief. 
One of the guiding principles of scientific research is verification; that is, any purported scientific discovery must be made open to other scientists for verification and confirmation or falsification. This Lipetz proceeds to do in respect of my study, but in a manner that constitutes neither a verification nor a replication. Deriving his data from a tertiary source (Charles Davis' bibliography and index of library science dissertations), which excludes abstracts or notations, he finds that between 36 and 54 percent of the studies employed some sort of quantification. The reader is, however, cautioned not to take these figures seriously since quantification in the library and information sciences is on the downward trend. Had Lipetz derived his figures from the Dissertation Abstracts International under the headings: information flow, leadership, leadership styles, communication, etc., his conclusion would have been different.

There is a serious danger in judging the contents of a study from its title. One easily remembers a book with the title The Sun King written by Nancy Mitford and published in New York in 1965 by Harper and Row. The book is a biography of the great French king, Louis XIV, but, as students of medical history know, it is also one of the most authoritative source books on 17 th century French medicine. True, Lipetz admits that his cursory survey was based on subjective judgment but I am not less astonished that one of the great apostles of a respectable profession could have overlooked so basic an aspect of his professional knowledge. We must remember that science is united, not by its subject matter but by its methodology. * Whenever a branch of factual knowledge is rejected by scientists, it is always on the basis of its methodology. This is because there is no cognitive body of knowledge called science. The various scientific disciplines are called scientific only because they apply methods of inquiry acceptable as scientific by scientists. This is why Peirce (1955, p.18) argues that "to satisfy our doubts, ... . it is necessary that a method should be found by which our beliefs may be determined by nothing human, but by some external permanency-by something upon which our thinking has no effect. . . . There are real things, whose characters are entirely independent of our opinions about them. . . ." In my view, bibliographic sources constitute one of such real things and Lipetz should have gone a little further to ensure that his bibliographic counts are independent of his personal whims and caprices. But even assuming that the percentage of studies in the library and information sciences that apply misquantification is, in the view of Lipetz, small, it would be interesting for Lipetz to tell his professional colleagues how great a misapplication of scientific tool would have to be to deserve a comment in a professional journal.

The Role of Theory. Lipetz's second concern is my assertion that the purpose of scientific research is the development of theory. Like many concepts in research, the word theory has been so diversely used that it threatens to become meaningless. Because of the diversity of its referents-including virtually everything from minor working hypotheses through comprehensive but vague and unordered speculations, to axiomatic systems of thought-use of the word often obscures rather than enhances understanding. When Lipetz lists the functions of research as "description, definition, theory, explanation of observed phenomena, prediction of future phenomena, and manipulative prescription to expand human capability or control," it is clear that his listing derives from a less than correct understanding of the notion and functions of scientific theory. I defined theory in my paper as "an internally connected and logically consistent proposition about the relation(s) between phenomena." Obviously I was not referring to what Merton (1968, p.39) calls "theories of the middle range." I was referring to (in the specific case of administration) total administrative theory in which observations about every aspect of administrative behavior, organization and change, find their complete and adequate explanation. I called this grand theory "nomological universal generalization." An historical sense of the challeng-

*The word science is derived from the Latin word scientia, itself from Latin sciens, the present participle of scire, "to know." It will be more linguistically precise to speak of scientific disciplines rather than science. 
ing contexts of theory building is sufficient to make us realize that this is not an easy goal to attain and I did make this clear in my paper when I stated that "a nomological universal generalization is very difficult to attain.'

Just before writing my response to Lipetz's observations about my paper, I wanted to reassure myself by making references to standard works on scientific research methodology. I was particularly interested in the way research scientists define theory and what they consider to be the functions of scientific theories. I was soon reassured by Fred N. Kerlinger (1973, p.9) who defined theory as ". . . a set of interrelated constructs (concepts), definitions, and propositions that present a systematic view of phenomena by specifying relations among variables, with the purpose of explaining and predicting the phenomena." It is obvious that explanation, description, definition, prediction, and manipulative prescription are functions of a viable scientific theory. The social sciences aim to provide general explanations to "why?" questions. When social scientists ask for an explanation of why a given phenomenon has taken place, they ask for a systematic and an empirical analysis of those antecedent factors in the given situation that are responsible for the occurrence of the phenomenon. In other words they ask for an explanation of its causes. No scientific theory is viable if it does not offer a satisfactory explanation of the phenomenon under study. The same applies to prediction; if one knows, for example, that manpower programs solve unemployment problems, one can predict that current rates of unemployment will be solved by the introduction of manpower programs. The expectation that scientific theories should lead to accurate predictions is based upon the argument that if it is known that $X$ causes $Y$, and that $X$ is present, then the prediction that $Y$ will occur can be made. ${ }^{*}$ Underlying this argument is the assumption that if a scientific theory or generalization is both logically valid and empirically true, that the antecedent conditions are sufficient for predicting the outcome, then the only reasons for failure in prediction can be (a) the theory or generalization is not true, or (b) the antecedent conditions are incorrectly perceived. Thus, if say, the problem of present unemployment remains unsolved, it is either because the theory that manpower programs solve unemployment problems is not true or because the activities aimed at solving unemployment problems are erroneously perceived as manpower programs. As Kerlinger (1972, p.10) further notes, " . . . by its very nature, a theory predicts . . . all else flow from theory."

A scientific theory also defines the boundary of its applicability. There is always a proviso, stated or implied, in every scientific theory. Every fledgling scientific researcher juggles with operational definition. No scientific theory can come into being that does not specify the class of phenomena to which it applies as well as the conditions under which it applies.

It is implicit in the above discussion that scientific theories are not built for theory-sake. Scientific theories are aimed at developing man's prediction and control of his environment, among other things. The search for scientific theories is a search for man's mastery of his environment; this is the central purpose of all scientific endeavour. What Lipetz ascribes to research are, in fact, the functions of scientific theories.

Let me discuss for a brief moment the central theme of my paper.

Empiricism. The thrust of my paper was empiricism, which I tried to relate to researches in the library and information sciences, specifically, with library administration. I used studies in the Dissertation Abstracts International only as a point of departure. My observation, which I still hold, is that a significant proportion of what pass for empirical research in the library and information sciences consists of general orientations towards data, rather than clearly formulated, verifiable statements of relationships between specified variables. They consist of many generalized concepts but few theories. When closely examined, as I intend to show in the near future, one finds in them largely descriptive empirical work with little

*Statements of the form "If $P$, then $q$ " called conditional statements in logic, are part of the core of scientific theory. They and the concepts or variables that go into them are the central ingredients of theories. 
theoretical orientation. My objection to such studies is not directed against them as empirical studies per se but against their implicit assumption, namely, that experiences alone can lead to new knowledge. As Karl Popper (1961, p.106) rightly noted: "The naive empiricist .... thinks that we begin by collecting and arranging our experiences, and so ascend the ladder of science . . ." Experience can only lead to new knowledge if it is followed by (a) reflective observation, (b) formation of abstract concepts and generalization, and (c) active experimentation in which the concepts and generalizations are tested for their repeatability.

Finally, Lipetz is "frightened-to death" because "a profession already aquiver with self-doubt" was subjected to critical appraisal. I only have to remind him that the various scientific disciplines have evolved in a slow process of growth. In this process criticism has always performed an important function. Through the continuous interchange of ideas and information it becomes possible to formulate commonly accepted rules and procedures and to develop corresponding methods and techniques. This system of rules and procedures is the normative component of the scientific methodology. It defines the "rules of the game," "and these, in turn, enable communication and scientific progress. Librarians need not be "frightened to death" by methodological criticism. As a developing scientific discipline this is inescapable. Even physics, with its apparently well-developed system of inquiry, is still not immune to methodological criticism. Some years ago, the theoretical physicist, Richard Feynman (1965, p.30) complained that ". . . today our theories of physics, the laws of physics, are a multitude of different parts and pieces that do not fit together very well." The library and/or information scientist who is "frightened to death" by methodological criticism runs the risk that, like the modern decor, the furniture of his mind will be bare and uncomfortable.

AMUSI ODI, Ph.D.

Program Director for Continuing Education

University of Pittsburg, Pittsburg, Pennsylvania

\section{BIBLIOGRAPHY}

Buchler, J., ed. Philosophical Writings of Peirce. New York: Dover, 1955.

Feynman. The Character of Physical Laws. London: Cox and Wyan, 1965.

Kerlinger, Fred N. Foundations of Behavioral Research. 2d ed. New York: Holt, 1973.

Merton, Robert K. Social Theory and Social Structure. New York: Free Pr., 1968.

Mitford, Nancy. The Sun King. New York: Harper, 1966.

Popper, Karl R. The Logic of Scientific Discovery. New York: Science Editions, 1961.

\section{SALARY COMPARISONS}

To the Editor:

Mel Westerman's research note, "Salary Comparisons between Academic Librarians and Instructional Faculty" (CERL, July 1982) is based on two invalid assumptions which render the study meaningless.

Westerman uses AAUP data that admittedly avoid the unresolved issues of faculty status and equivalent education and experience recommended in the ACRL Standard. In doing so Westerman, along with many academic librarians writing on this subject, refuses to realistically compare criteria for library positions with the basic credential, responsibility and experience criteria of the dominant group in academic culture. The ACRL statement that "the salary scale for librarians should be the same as that for other academic categories with equivalent education and experience" suggests a comparison with only specific academic groups or positions. It does not suggest a comparison with the salaries of all academic categories as was done by Westerman.

The second assumption presumes that one can compare academic rank salaries with administrative position salaries. Criteria for hiring, promotion and salaries and the weight given to education and experience are different for the two groups. Academic appointment 
is based primarily on a minimum requirement of an earned doctorate augmented by research accomplishments and teaching experience. That of administration is based on special knowledge and skills, administrative experience and a range of academic degrees from bachelor's to doctorate depending on the position. The fact that academic librarians have been traditionally grouped by administrative position is insufficient reason to use that classification in a comparison with the equally traditional academic ranks. The result of such an attempt is without value. All it does is reveal a lack of understanding of college and university personnel practices and their underlying rationale.

My own experiences as a librarian with full academic status for the past ten years coupled with innumerable conversations with teaching colleagues and other academic librarians about academic rights and responsibilities led to extensive reading and study of the literature and considerable thought about the academic status of librarians. I am convinced now that academic librarians must be willing to educate and socialize themselves as academic persons if they want equity with the faculty. Any other route invites professional role confusion and an admission of second-class citizenship in academe.

In my opinion studies such as this one display the very weaknesses which place research in librarianship at disadvantage. Yet even with an improvement of research design, salary comparison between academic librarians and faculty does little to help librarians understand their past, present, and possible future identities on deeper levels.

We need to stop trying to find fault only with faculty and administration and look within our own profession for factors which have placed us at odds with ourselves and the academic culture.

\section{JACQUELIN PAGE}

Doctoral Student in Education, St. Louis University

(Formerly Assistant Professor, Biomedical Library

School of Dental Medicine, Southern Illinois University)

To the Editor:

Ms. Page states two assumptions for my study which I have not stated. She states that one of my assumptions is a refusal "to realistically compare criteria for library positions with the basic credential, responsibility and experience criteria of the dominant group in academic culture," and that another is "that one can compare academic rank salaries with administrative position salaries." Her conclusion that these assumptions "render the study meaningless" is, therefore, invalid. I accept her "assumptions" as comments on the topic of salary comparisons, in which she and I share a serious interest.

Credentials are one of the basic factors in occupational salary structure considerations. It is often posited that doctors and attorneys "deserve" high incomes because of the time and expense incurred in their extensive and specialized training. But, this principle decreases in persuasiveness when comparisons of their salaries to those of professors in the humanities are made. A more focused comparison reveals a large difference in salaries between faculty members in humanities fields and those in the petroleum or chemical engineering departments at the same institutions. It is my position that the education and experience required to be a petroleum engineering professor are equivalent to the education and experience required to be a humanities professor, with the sole difference being subject content. Other, external factors are affecting the salary difference in this comparison. I generalize that a rigid model of equivalents is impossible in academic salary structure considerations.

Choosing a definition for the word "equivalent" becomes an activity of critical importance when interpreting the ACRL "standards." Gleanings from the Webster's Third New International Dictionary include meanings such as: - equal in force or amount; -like in significance or import; - equal in value; -corresponding or virtually identical, esp. in effect or function. These definitions suggest to me that the entry-level degree requirement for one field might be different from, but equivalent to another field in academia. As evidence, faculty in the fields of art, music and theater education have traditionally held lower-level degree requirements because of the special creative attributes of their fields. I hold the posi- 
tion that the unique attributes of librarianship earn it a role as an academic discipline with full faculty responsibilities, privileges and benefits. But, to transmute library faculty into instructional faculty destroys the uniqueness of contributions of librarians to their institutions' educational objectives. Likewise, to ignore the contrast between the administrative orientation in libraries and the research or creative orientation of instructional departments denies basic characteristics of each. The differences should harmonize and complement one another. They are, at the least, equal in value.

Research on college and university personnel practices is subject to the restrictions of social sciences research, of which it is a part. In that context, to address a research topic from a new perspective, as I attempted to do, might not immediately discover a solution to its problems, but it may contribute to an eventual solution. My instructional faculty colleagues respect me more for an inquisitive and creative approach to problems than for a fawning mimicry of their status.

MEL WESTERMAN

University Libraries, Pennsylvania State University, University Park

\section{APPLAUSE AND REGRETS}

To the Editor:

Some librarians will undoubtedly label Professor Lacey (CERL, March 1982) "oldfashioned." I, how ever, would like to applaud him for providing a perspective sometimes pushed aside in the often too swift and too casual reach for the future. We library professionals need more honest communication from our users about their concerns relating to library technological innovation.

As one who has tended to be an early adopter of innovation in libraries, I have become intrigued by the characteristics of the later adopters and resistors of innovation. Professor Lacey is not alone, by any means. His is a valid and valuable stance. For those who would disregard Lacey's comments, I recommend Donald Klein's essay "Some Notes on the Dynamics of Resistance to Change: The Defender Role" in Bennis, Benne, and Chin's The Planning of Change (Holt, 1969).

It was encouraging to hear from C. Lee Jones of the Council on Library Resources, Inc., at the 1982 AMIGOS Technical Session that his group is investigating the characteristics of nonusers as well as users of the online catalog innovation while it is still early in its diffusion.

I have recently completed a pilot study to identify differences between faculty resistors and adopters of library technological innovations and hope to do further research in this area. I invite responses.
BETSY BOWERS ALDRIDGE, Assistant Professor
East Central Oklahoma State University, Ada
(Doctoral Student, Texas Woman's University, Denton)

To the Editor:

I was sorry to find a minor error in my article "The Natural Alliance between Librarians and English Teachers" (CERL, September 1982). Someone indicated that the survey was conducted at the University of Nebraska (p.380 last line, and first paragraph p.381). I moved to Nebraska, but the survey was conducted at, and through the support of, Brigham Young University, Utah. Therefore, I regret that your editorial insertion was inaccurate. It would be nice if CERL would acknowledge BYU's support role in the gathering of the material which supplied the background for the article.

JAMES E. FORD

Department of English, University of Nebraska-Lincoln 


\section{Announcing Part 2 PAPERS OF THE NAACP}

Editorial Adviser: August Meier

University Professor of History, Kent State University

\section{Part 2: Personal Correspondence of Selected NAACP Officials, 1919-1939}

The materials in this collection contain a wealth of insight on the lives and work of upper-echelon NAACP officials over two critical decades of the Association's history. The largest selections are those pertaining to Thurgood Marshall and Walter White, the Association's Special Assistant Counsel and Executive Secretary, respectively - neither of whom has yet been the subject of thorough biography. Other officials represented are Special Counsel Charles Houston, Special Assistant to the Secretary Juanita Jackson, Executive Secretary James Weldon Johnson, Branch Coordinator E. Frederick Morrow, Chairman of the Board of Directors Mary White Ovington, Field Secretary Dr. William Pickens, and Assistant Executive Secretary Roy Wilkins.

The correspondence ranges from routine office matters to musings and speculations upon the goals and programs of the Association. The selections for Charles Houston and ThurgoodMarshall, for example, are filled with comments on pending NAACP litigation. The materials on the two executive secretaries, James Weldon Johnson and Walter White, contain portions of their literary correspondence as well as glimpses of the view from the apex of the Association's structure. Not only is this correspondence extremely valuable, but it is also a largely untapped source-now published for the first time-for the history of the NAACP and the entire American civil rights movement.

Part 1: Meetings of the Board of Directors, Records of Annual Conferences, Major Speeches, and Special Reports, 1909-1950

Part 1 includes thousands of pages of minutes of meetings of the board of directors, significant records of the Association's annual conferences and meetings, and voluminous reports and special correspondence. Part 1 has been praised as the premier documentary collection on the major developments toward racial equality during this century.

This is a valuable resource for the study of Black history and should be made available to smaller libraries as well as major research institutions. It is a welcome first installment on some of the most important research materials in twentieth-century Black history.

\section{-Dan T. Carter, Department of History, Emory University}

These papers are indispensable for understanding not only the NAACP but also the emergence of the entire twentieth-century civil rights movement as well.

-Robert L. Zangrando, Department of History, University of Akron

This is the one major collection that touches upon virtually every critical social, political, and educational issue concerning Afro-Americans during the years 1909 through 1950. No student or scholar of the Black experience in twentieth-century American can afford to bypass or ignore this pivotal collection of primary sources now made so conveniently accessible by University Publications of America.

-Darlene Clark Hine, Department of History, Purdue University

PAPERS OF THE NAACP

Part 1: Meetings of the Board of Directors, Records of Annual Conferences, Major Speeches, and Special Reports, 1909-1950.

$35 \mathrm{~mm}$ microfilm (28 reels) with printed guide. Price: $\$ 1700$. Available now. ISBN 0-89093-397-9.

Part 2: Personal Correspondence of Selected NAACP Officials, 1919-1939.

$35 \mathrm{~mm}$ microfilm (20 reels) with printed guide. Price: \$1200. Available now. ISBN 0-89093-511-4.

Kindly direct all orders and inquiries to:

UNIVERSITY PUBLICATIONS OF AMERICA, INC. 44 North Market Street • Frederick, MD $21701 \bullet$ (301) 694-0100 